\title{
Encapsulamento de Trichoderma inhamatum para o Controle Biológico de Rhizoctonia solani na Propagação Clonal de Eucalyptus
}

\author{
Reginaldo G. Mafia ${ }^{1}$, Acelino C. Alfenass ${ }^{1}$, Luiz A. Maffia ${ }^{1}$, Gizella M. Ventura ${ }^{1}$ \& Eugênio A. Sanfuentes ${ }^{2}$ \\ ${ }^{1}$ Departamento de Fitopatologia, Universidade Federal de Viçosa, CEP 36571-000, \\ Viçosa, MG, Brasil, e-mail: aalfenas@mail.ufv.br; ${ }^{2}$ Departamento de Silvicultura, \\ Universidad de Concepcion, Victoria 631, Casilla 154-C, Concepcion, Chile
}

(Aceito para publicação em 16/10/2002)

Autor para correspondência: Acelino Couto Alfenas

MAFIA, R.G., ALFENAS, A.C., MAFFIA, L.A., VENTURA, G.M. \& SANFUENTES, E.A. Encapsulamento de Trichoderma inhamatum para o controle biológico de Rhizoctonia solani na propagação clonal de Eucalyptus. Fitopatologia Brasileira 28:101-105. 2003.

\section{RESUMO}

Testou-se um novo sistema para o encapsulamento de Trichoderma inhamatum em grânulos de alginato de sódio, visando o controle biológico de Rhizoctonia solani, agente etiológico da mela de estacas/miniestacas de Eucalyptus spp. para enraizamento. No novo sistema idealizado, foi utilizado um aparato simples capaz de substituir eficientemente o equipamento (Bomba Peristáltica) anteriormente utilizado, sendo possível aumentar a produção de 594 grânulos/min para aproximadamente 6.734 grânulos/min. Com este novo sistema, um isolado de T. inhamatum (UFV - 03) foi encapsulado em grânulos contendo as fontes alimentares: farelo de trigo, palha de arroz, farelo de aveia, folhas de eucalipto ou farelo de milho na concentração de $50 \mathrm{~g} / \mathrm{l}$. Na segunda etapa, a melhor fonte alimentar foi testada nas concentrações de 0 a $60 \mathrm{~g} /$ 1. Os grânulos foram veiculados em substrato de enraizamento de eucalipto na concentração de $2 \%(\mathrm{p} / \mathrm{p})$ inoculado com micélio triturado de $R$. solani ( $2 \mathrm{mg} / \mathrm{g}$ de substrato) e a atividade saprofítica do patógeno foi quantificada por meio do método de iscas. Posteriormente, os grânulos produzidos com a fonte alimentar e concentração que promoveram maior inibição do desenvolvimento de $R$. solani foram utilizados para determinar o tempo mínimo de pré-incubação e competição para supressão do patógeno, com a mesma metodologia. Observou-se aumento da supressão da atividade saprofítica de $R$. solani ao acréscimo de uma fonte alimentar. Daquelas testadas, farelo de trigo foi a melhor. Além disso, houve interação significativa e positiva ao aumento de sua concentração na formulação.

Palavras-chave adicionais: biocontrole, antagonista, formulação granulada.

\section{ABSTRACT}

Encapsulation of Trichoderma inhamatum for the biological control of Rhizoctonia solani in clonal propagation of Eucalyptus

A new system of encapsulating Trichoderma inhamatum in sodium alginate was developed for controlling Rhizoctonia solani blight of Eucalyptus spp. cuttings/mini-cuttings used for rooting. In this system, simpler materials and apparatus efficiently replaced the peristaltic pump, increasing pellet production from 594 pellets/ min to approximately 6,734 pellet/min. An isolate of $T$. inhamatum (UFV-3) was encapsulated in pellets containing wheat bran, rice husk, oat bran, eucalyptus leaf or maize meal as food base at a concentration of $50 \mathrm{~g} / \mathrm{l}$. In the second step, the best food base was evaluated at the concentrations ranging from 0 to $60 \mathrm{~g} / 1$. The pellets were added to $R$. solani infested ( $2 \mathrm{mg}$-macerated mycelium/g) eucalyptus rooting substrate at the rate of $2 \%(\mathrm{w} / \mathrm{w})$ and the saprophytic activity of the pathogen was quantified with a baiting technique. The pellets containing wheat bran, which maximally inhibited $R$. solani, were used to determine the minimum preincubation and competition period for pathogen suppression. Increasing food base concentration in the pellets increased suppression of $R$. solani. Additionally, there was a significant positive interaction between food base concentration in the formulation and pathogen suppression.
O Brasil possui atualmente a maior área reflorestada com espécies de eucalipto (Eucalyptus spp.) no mundo. As plantações destinam-se principalmente à produção de celulose e carvão (Campinhos Jr., 1999). A propagação clonal de Eucalyptus spp. foi iniciada comercialmente em meados da década de 80 (Campinhos \& Ikemori, 1983). Esta técnica possibilita a formação de talhões homogêneos formados por genótipos silvicultural e tecnologicamente superiores e resistentes a doenças. No entanto, as condições ambientais requeridas para o enraizamento são extremamente favoráveis à incidência de fungos fitopatogênicos, principalmente Rhizoctonia solani Kühn (Ferreira, 1989; Alfenas et al., 1997).
Espécies de Trichoderma aplicadas de forma isolada, associadas com Gliocladium virens Miller, Giddens \& Foster ou com espécies bacterianas têm sido extensivamente estudadas no controle de $R$. solani (Hadar et al., 1979; Elad et al., 1980; Harman et al., 1980; Chet \& Baker, 1981; Nelson et al., 1983; Beagle-Ristaino \& Papavizas, 1985; Kwok et al., 1987; Lewis \& Papavizas, 1987; Knudsen \& Bin, 1990; Lewis et al., 1998). A ação antagonista de Trichoderma spp. ocorre principalmente em função da produção de metabólicos voláteis e não voláteis, como também pelo hiperparasitismo e pela competição por espaço, nutrientes e oxigênio (MartinsCorder \& Melo, 1998). 
A inexistência de fungicidas registrados para a eucaliptocultura e a baixa eficiência dos produtos químicos impossibilita o seu uso na propagação clonal de Eucalyptus spp. (Silveira, 1996). Neste sentido, estudos de controle biológico utilizando espécies de Trichoderma têm sido conduzidos no laboratório de Patologia Florestal - UFV (Alonso, 1997; Sanfuentes, 2000). Nestes e em outros estudos tem-se observado o aumento na atividade dos antagonistas quando estes são aplicados após seu cultivo em substratos que lhes sirvam de base nutricional, o que permite um rápido crescimento e colonização do substrato, bem como, em alguns casos, o estabelecimento do hiperparasitismo. Desta forma, com o objetivo de desenvolver uma formulação à base de um isolado de T. inhamatum (UFV-3), reconhecidamente eficiente no controle biológico de $R$. solani, construiu-se um aparato simples para a produção massal dos grânulos de alginato de sódio. Em uma segunda etapa, o efeito da adição de fonte alimentar, concentração, tempo de competição e pré-incubação foram avaliados na supressão da atividade saprofítica de $R$. solani.

O isolado de T. inhamatum utilizado (UFV-3), foi anteriormente pré-selecionado quanto à capacidade supressiva a Rhizoctonia spp., sob condições controladas (Alonso, 1997), e mantido a $10^{\circ} \mathrm{C}$, em tubos com batata-dextrose-ágar (BDA). Empregou-se o isolado RH-18 multinucleado de $R$. solani (AG-1B) obtido de folhas de eucalipto com sintomas de queima foliar coletadas em jardim clonal (Silveira, 1996).

Para a produção massal do antagonista, discos de cultivo em BDA foram repicados para Erlenmeyers de 1.000 $\mathrm{ml}$ de capacidade, contendo $500 \mathrm{ml}$ de meio líquido de batatadextrose (BD), seguindo-se incubação a $27{ }^{\circ} \mathrm{C}$, sob agitação rotativa, a $120 \mathrm{rpm}$. A massa de micélio foi coletada e lavada três vezes em água destilada esterilizada, sob vácuo (bomba DIA-PUMP $®$, FANEM, Brasil). Após remover o excesso de água, por prensagem em papel de filtro, a massa de micélio foi armazenada a $4{ }^{\circ} \mathrm{C}$ por $24 \mathrm{~h}$, no máximo, antes de seu uso.

Para produzir a formulação do tipo granulada, seguiuse metodologia adaptada de Lewis \& Papavizas (1985). Para isso, $20 \mathrm{~g}$ de alginato de sódio (VETEC, MG Química Comercial, Brasil) foram dissolvidos em $750 \mathrm{ml}$ de água destilada esterilizada, em agitador magnético, a $40^{\circ} \mathrm{C}$. $\mathrm{O}$ farelo de trigo utilizado como fonte alimentar na concentração de $50 \mathrm{~g} / \mathrm{l}$ foi homogeneizado em moinho elétrico, passado em peneira de $0,42 \mathrm{~mm}$ e esterilizado a seco, a $90^{\circ} \mathrm{C}$, durante 24 h. Após a esterilização, o farelo foi misturado a $250 \mathrm{ml}$ de suspensão de micélio triturado do antagonista, na proporção de $17 \mathrm{~g}$ de micélio triturado/l. Essa suspensão foi adicionada à solução de alginato de sódio $(750 \mathrm{ml})$ e gotejada em solução de Cloreto de Cálcio (SIGMA CHEMICAL Co) a 0,25 M, com o auxílio de uma bomba peristáltica de três saídas (P-3 PHARMACIA, USA), velocidade 10 , o que permitiu a formação de grânulos esféricos de diâmetro regular. Os grânulos formados, mantidos por, pelo menos, 10 min nesta solução, foram lavados em água de torneira, para remover o excesso de $\mathrm{CaCl}_{2}$, e submetidos à secagem sob ventilação forçada, durante dois dias a $26^{\circ} \mathrm{C}$ e quatro dias a $30^{\circ} \mathrm{C}$.
Apesar do sucesso do encapsulamento utilizando a bomba peristáltica, com o objetivo de reduzir o tempo necessário para a produção do produto biológico, foi construído um aparato simples a partir de 18 ponteiras $(10 \mathrm{ml})$ acopladas em uma caixa plástica do tipo gerbox $(11$ x 11 x $3 \mathrm{~cm})$ suspensa numa haste metálica (Figura 1). Para testar a sua eficiência, os grânulos foram produzidos como anteriormente, substituindo apenas a bomba peristáltica utilizada anteriormente pelo aparato descrito.

É possível obter sucesso no encapsulamento de fungos antagonistas em grânulos de alginato de sódio, com o auxílio de equipamentos como a bomba peristáltica. Porém, a maior dificuldade em tornar viável a sua utilização no controle de fitopatógenos em condições de campo está na produção massal de produtos para controle biológico. Neste sistema, utilizandose o modelo de bomba peristáltica descrita anteriormente, a produção é de aproximadamente 594 grânulos/min. Porém, com o aparato desenvolvido, foi possível aumentar a produção para 6.734 grânulos/min. Ademais, não foram constatadas diferenças significativas quanto ao diâmetro dos grânulos produzidos em ambos os sistemas. Além disso, observou se que esta variável variou em função do grau de hidratação dos grânulos, sendo em média igual a $2 \mathrm{~mm}$ nos grânulos completamente hidratados.

$\mathrm{Na}$ segunda etapa, o antagonista (UFV-3) foi encapsulado e se utilizou como fonte alimentar: farelo de trigo, palha de arroz, farelo de aveia), folhas de eucalipto ou farelo de milho, na concentração de $50 \mathrm{~g} / 1$. Posteriormente, a melhor fonte alimentar foi testada nas seguintes concentrações: 10 ,

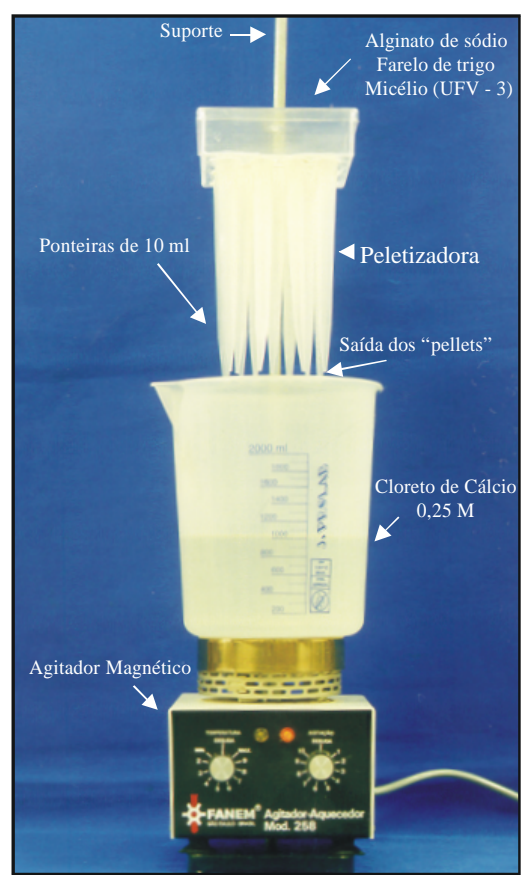

FIG. 1 - Aparato utilizado para a produção massal de "pellets" de alginato de sódio acoplada a uma haste metálica, tendo abaixo solução de $\mathrm{CaCl}_{2}$ $(0,25 \mathrm{M})$ sob agitação. 
Encapsulamento de Trichoderma inhamatum para o controle biológico de...

20, 30, 40, 50 e $60 \mathrm{~g} / \mathrm{l}$.

Antes da montagem dos ensaios, amostras de 60 "pellets" de cada tratamento foram semeadas em meio BDA $(\mathrm{pH} 5,0)$ para determinar a viabilidade do antagonista e certificar a inexistência de contaminantes fúngicos e, ou, bacterianos, pela observação das colônias formadas. Em nenhum tratamento foi observada contaminação dos grânulos, bem como, $100 \%$ de viabilidade foi obtido mesmo para os grânulos que permaneceram até três meses armazenados a $10{ }^{\circ} \mathrm{C}$.

Os grânulos com as diferentes fontes alimentares foram incorporados em substrato de enraizamento $(70 \%$ de composto de casca de eucalipto : $30 \%$ de vermiculita) esterilizado, na proporção de $2 \%(\mathrm{p} / \mathrm{p})$ em três amostras de $100 \mathrm{~g}$ contidas em caixas plásticas tipo gerbox $(11,5 \times 11,5 \times 3,5 \mathrm{~cm})$, seguindo-se um delineamento inteiramento casualizado, com três repetições por tratamento. Após $72 \mathrm{~h}$ de incubação, a 27 ${ }^{\circ} \mathrm{C}$ no escuro, o substrato foi infestado com o isolado RH-18 de $R$. solani $(2 \mathrm{mg} / \mathrm{g}$ de substrato) seguindo-se a incubação nas mesmas condições anteriores. Em intervalos de cinco dias, estimou-se a densidade de inóculo de Rhizoctonia sp. pelo método de iscas (Sanfuentes et al., 1998). Para tanto, 30 segmentos de ramos de eucalipto $(15 \times 3 \mathrm{~mm})$ por repetição foram inseridos no substrato, incubando-se no escuro a 27 ${ }^{\circ} \mathrm{C}$. Após $48 \mathrm{~h}$, as iscas foram retiradas, lavadas e desinfestadas com $\mathrm{NaClO}$, a 1000 ppm de $\mathrm{Cl}_{2}$ ativo, por 3 min, enxaguada duas vezes com água destilada e esterilizada, e semeadas em meio de ágar-água acidificado ( $\mathrm{pH}$ 5). Após 24-48 h, avaliouse, sob microscópio, a presença de estruturas do patógeno.

Posteriormente, os grânulos produzidos com a fonte alimentar e concentração que promoveram maior supressividade, foram testados em diferentes tempos de incubação antes e após a infestação com o patógeno, obtendo-se diferentes períodos de competição e pré-incubação do antagonista em relação ao patógeno. Assim, em intervalos de três dias, infestou-se o substrato contido em caixas tipo gerbox do antagonista e do patógeno, obtendo-se diferentes períodos de pré-incubação e competição entre ambos, seguindo-se a mesma metodologia e condições descritas anteriormente.

A aplicação de encapsulados granulados ("pellets") contendo microrganismos antagonistas representa uma excelente inovação para o controle de fungos fitopatogênicos, necessitam, porém, em sua formulação de uma fonte alimentar (Lewis \& Papavizas, 1987).

No presente trabalho, os resultados obtidos demonstraram o efeito do antagonista T. inhamatum (UFV - 3) na supressão da atividade saprofítica de $R$. solani. No entanto, observou-se grande variação no nível de supressão em resposta as diferentes fontes alimentares utilizadas na formulação.

A importância de se utilizar uma fonte alimentar nas formulações de antagonistas para o controle de fungos fitopatogênicos já foi observada em outros estudos. Dentre as fontes testadas, o farelo de trigo destacou-se e diferiu das demais, reduzindo a densidade de inóculo de $R$. solani para $11,1 \%$ e $5,6 \%$ a partir do décimo e décimo quinto dias, respectivamente (Tabela 1 ).
Trichoderma spp. proliferam abundantemente, especialmente quando aplicado como micélio jovem veiculado em farelo de trigo (Lewis \& Papavizas, 1985). Com o farelo de trigo apesar de não ter influenciado no crescimento radial de isolados de Trichoderma spp., obteve-se maior densidade de hifas (Knudsen \& Bin, 1990). Esta fonte alimentar foi considerada como o melhor meio para o crescimento e esporulação de T. harzianum (Hadar et al., 1979). Em vista destes resultados, o farelo de trigo foi selecionado como base alimentar na aplicação de $T$. inhamatum.

Com os grânulos contendo farelo de milho ou palha de arroz, apesar de não se ter obtido a maior supressividade, verificou-se redução da densidade de inóculo para 30 e 23,3\%, respectivamente, após 15 dias de incubação.

Outros materiais podem ser utilizados para a produção de formulados à base de microrganismos antagonistas. Por exemplo, grânulos de celulose foram utilizados após a ativação com ácido diluído (0,05 N HCl) (Lewis et al., 1998). Estes autores observaram a formação de hifas jovens e com crescimento ativado após dois-três dias, com redução do tombamento de mudas provocado por $R$. solani e o crescimento deste patógeno no solo.

Observou-se incremento significativo na supressão do patógeno, com o aumento da concentração da fonte alimentar (farelo de trigo) (Figura 2). O modelo geral que melhor explicou a relação entre a atividade saprofítica de $R$. solani, expressa pela relação da porcentagem de iscas colonizadas (Y) com a concentração da fonte alimentar (A) e o tempo de incubação (B) foi $\mathrm{Y}=97,88-0,34 \mathrm{~A}-0,65 \mathrm{~B}-0,07 \mathrm{AB}$.

$\mathrm{Na}$ maior concentração testada, a supressão da atividade saprofítica de $R$. solani foi bastante elevada. Elad et al., (1980) observaram que o controle biológico correlacionou positivamente em relação ao incremento de $T$. harzianum

TABELA 1 - Atividade saprofítica de Rhizoctonia solani, expressa pela percentagem de colonização de iscas de eucalipto (Eucalyptus spp.) por Rhizoctonia sp., em função da formulação de Trichoderma inhamatum contendo diferentes fontes alimentares

\begin{tabular}{lcccc}
\hline \multirow{2}{*}{ Tratamento } & \multicolumn{4}{c}{ Atividade saprofítica de $\boldsymbol{R}$. solani $(\%)$} \\
\cline { 2 - 5 } & 0 dia & 5 dias & $\mathbf{1 0}$ dias & $\mathbf{1 5}$ dias \\
\hline Testemunha 1 ${ }^{(1)}$ & $95,6 \mathrm{a}{ }^{(2)}$ & $96,7 \mathrm{a}$ & $96,7 \mathrm{a}$ & $96,7 \mathrm{a}$ \\
Testemunha 2 $^{(3)}$ & $91,1 \mathrm{a}$ & $84,4 \mathrm{ab}$ & $83,3 \mathrm{a}$ & $78,9 \mathrm{~b}$ \\
Folha de eucalipto & $74,4 \mathrm{bc}$ & $96,7 \mathrm{a}$ & $98,9 \mathrm{a}$ & $96,7 \mathrm{a}$ \\
Farelo de aveia & $87,8 \mathrm{ab}$ & $74,4 \mathrm{~b}$ & $47,8 \mathrm{~b}$ & $43,3 \mathrm{c}$ \\
Farelo de milho & $87,8 \mathrm{ab}$ & $80,0 \mathrm{ab}$ & $40,0 \mathrm{~b}$ & $30,0 \mathrm{~d}$ \\
Palha de arroz & $71,1 \mathrm{c}$ & $71,1 \mathrm{bc}$ & $36,7 \mathrm{~b}$ & $23,3 \mathrm{~d}$ \\
Farelo de trigo & $72,2 \mathrm{bc}$ & $54,4 \mathrm{c}$ & $11,1 \mathrm{c}$ & $5,6 \mathrm{e}$ \\
\hline
\end{tabular}

(1) Substrato não tratado com grânulos.

(2) Em cada dia, as médias seguidas pela mesma letra, não diferem significativamente entre si, pelo teste de Tukey $(\mathrm{p}<0,05)$.

(3) Substrato tratado com grânulos sem fonte alimentar. 
formulado em farelo de trigo aplicado ao solo e negativamente com o nível de infestação pelos patógenos.

Não se observou diferença significativa quanto à redução da sobrevivência e crescimento saprofítico de $R$. solani no solo quando se utilizou pequenas $(3,0-7,5 \mathrm{~g} / \mathrm{l})$ ou grandes (30 g/l) quantidades de biomassa dos antagonistas (Trichoderma spp. e Gliocladium spp.). Dessa forma, a utilização de doses crescentes de uma fonte alimentar parece ser mais apropriada na formulação dos antagonistas (Lewis \& Papavizas, 1987). Segundo estes autores, o tempo em que os "pellets" contendo os antagonistas são adicionados ao solo em relação ao patógeno é muito importante para a efetividade do biocontrole. Da mesma forma, no presente trabalho, observaram-se diferenças na supressividade da atividade saprofítica de $R$. solani, em resposta aos diferentes períodos de aplicação do antagonista em relação ao patógeno e quanto ao tempo de competição entre ambos.

Observou-se relação significativa e negativa entre a atividade saprofítica do patógeno e o tempo de competição. Assim, o mais importante para o controle biológico de $R$. solani, em substrato de enraizamento à base de casca de eucalipto, é o tempo em que o antagonista compete com o patógeno, independentemente do período de pré-incubação de ambos (Figura 3).

Outros fatores devem ser considerados no estabelecimento da supressividade de compostos à base de casca de árvores. A idade do composto, ou seja, o tempo de compostagem é um dos fatores a serem considerados no resultado de compostos supressivos e condusivos (Nelson et al., 1983). Um solo supressivo a $R$. solani continha uma maior população de T. hamatum e esta maior taxa de antagonistas foi influenciada pelo $\mathrm{pH}$ do solo, pois $\mathrm{pH}$ mais ácido estimula a proliferação de Trichoderma spp. (Chet \& Baker 1981).

Segundo os resultados deste e de outros estudos, a aplicação de microrganismos veiculados em formulações do

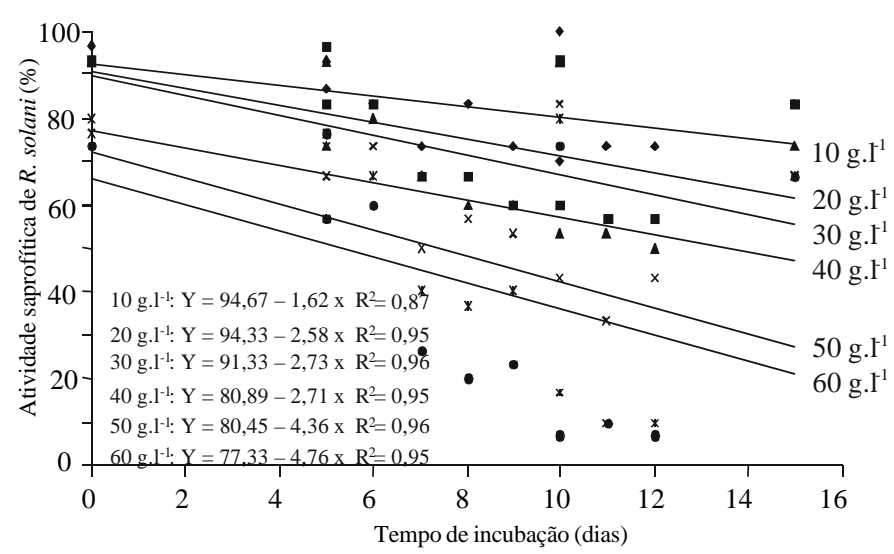

FIG. 2 - Relação entre a atividade saprofítica de Rhizoctonia solani (RH - 18), expressa pela porcentagem de iscas colonizadas ( $Y$ ) em substrato de enraizamento, e o tempo de incubação $(X)$ para as diferentes concentrações de farelo de trigo testadas.

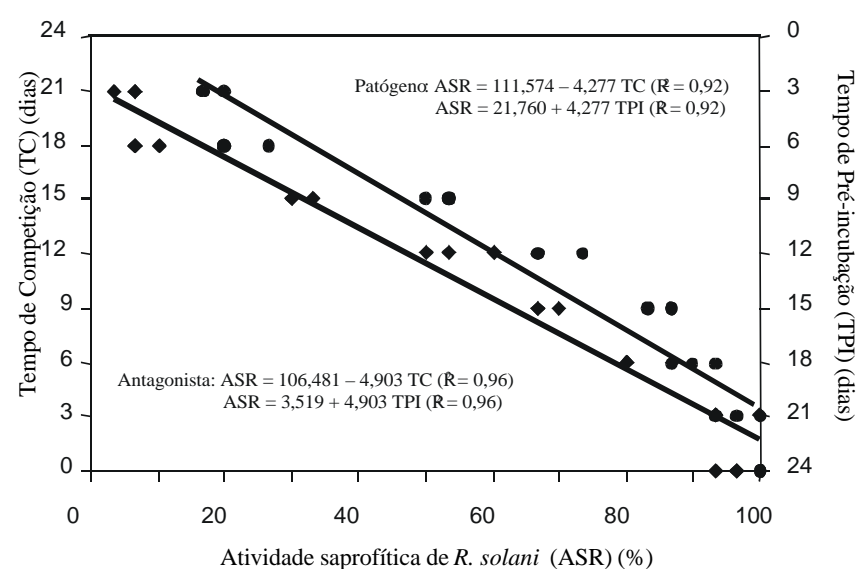

FIG. 3 - Relação entre o tempo de competição (TC), préincubação (TPI) e atividade saprofítica de Rhizoctonia solani (ASR), expressa pela porcentagem de iscas colonizadas (\%) em substrato de enraizamento, submetido à pré-incubação do antagonista (UFV - 3) e do patógeno (RH - 18).

tipo encapsulado granulado é alternativa viável para o controle de fitopatógenos. Especificamente no patossistema estudado, a veiculação de isolados de Trichoderma spp. em grânulos de alginato de sódio, contendo farelo de trigo como fonte alimentar na concentração de 50 a $60 \mathrm{~g} / \mathrm{l}$, aplicados para permitir pelo menos 18 dias de competição, é uma excelente forma de controle biológico de $R$. solani.

\section{REFERÊNCIAS BIBLIOGRÁFICAS}

ALFENAS, A.C., SILVEIRA, S.F. \& SANFUENTES, E.A. Current status and control strategies of disease associated to clonal propagation of Eucalyptus in: Brazil. IN: IUFRO Conference on silviculture and improvement of Eucalyptus. Proceedings. Colombo: EMBRAPA. Centro Nacional de Pesquisas Florestais, volume 4. 1997.

ALONSO de, S.K. Trichoderma longibranchiatum e T. inhamatum como agentes de controle da mela de estacas de eucalipto, causada por Rhizoctonia. (Tese de Doutorado).Viçosa, MG, UFV, Imprensa Universitária, 1997.

BEAGLE-RISTAINO, J.E. \& PAPAVIZAS, G.C. Survival and proliferation of propagules of Trichoderma spp. and Gliocladium virens in soil and in plant rhizospheres. Phytopathology 75:729732. 1985.

CAMPINHOS, E.J. \& IKEMORI, Y.K. Nova técnica para produção de mudas de essências florestais. IPEF 23:47-52. 1983.

CAMPINHOS JR., E. Sustainable plantations of high-yield Eucalyptus trees for production of fiber: the Aracruz case. New Forests 17:129-143. 1999.

CHET, I. \& BAKER, R. Isolation and biocontrol potential of Trichoderma hamatum from soil naturally suppressive to Rhizoctonia solani. Phytopathology 71:286-290. 1981.

ELAD, Y., CHET, I. \& KATAN, J. Trichoderma harzianum: A biocontrol agent effective against Sclerotium rolfsii and Rhizoctonia solani. Phytopathology 70:119-121. 1980. 
Encapsulamento de Trichoderma inhamatum para o controle biológico de...

FERREIRA, F.A. Patologia Florestal: principais doenças florestais no Brasil. Viçosa, Sociedade de Investigações Florestais, 1989.

HADAR, Y., CHET, I. \& HENIS, Y. Biological control of Rhizoctonia solani damping-off with brean culture of Trichoderma harzianum. Phytopathology 69:64-68. 1979.

HARMAN, G.C., CHET, I. \& BAKER, R. Trichoderma hamatum effects on seed and seedlings diseases induced in radish and pea by Pythium spp. or Rhizoctonia solani. Phytopathology 70:11671172. 1980.

LEWIS, J.A. \& PAPAVIZAS, G.C. Characteristics of alginate pellets formulated with Trichoderma and Gliocladium and their effect on the proliferation of the fungi in soil. Plant Pathology 34:571-577. 1985.

LEWIS, J.A. \& PAPAVIZAS, G.C. Application of Trichoderma and Gliocladium in alginate pellets for control of Rhizoctonia damping-off. Plant Pathology 36:438-446. 1987.

LEWIS, J.A., LARKIN, R.P. \& ROGERS, D.L. A formulation of Trichoderma and Gliocladium to reduce damping-off caused by Rhizoctonia solani and saprophytic growth of the pathogen in soilless mix. Plant Disease 82:501-506. 1998.

KNUDSEN, G.R. \& BIN, L. Effects of temperature, soil moisture, and wheat bran on growth of Trichoderma harzianum from alginate pellets. Phytopathology 80:724-727. 1990.
KWOK, O.C.H., FAHY, P.C., HOITINK, H.A J. \& KUTER, G.A. Interactions between bacteria and Trichoderma hamatum in supression of Rhizoctonia spp. damping-off in bark compost media. Phytopathology 77:1206-1212. 1987.

MARTINS-CORDER, M.P. \& MELO, I.S. Antagonismo "in vitro" de Trichoderma spp. a Verticillium dahliae KLEB. Scientia Agrícola 55: 1-7. 1998.

NELSON, E.B., KUTER, G.A. \& HOITINK, H.A J. Effects of fungal antagonists and compost age on supression of Rhizoctonia spp. damping-off in container media amended with compost hardwood bark. Phytopathology 73:1457-1462. 1983.

SILVEIRA, S.F. Etiologia e controle da mela de estacas e da queima de folhas de eucalipto, causada por Rhizoctonia spp. (Tese de Doutorado). Viçosa, MG, UFV, Imprensa Universitária, 1996.

SANFUENTES, E.A., ALFENAS, A.C., REIS, M.J. \& MAFFIA, L.A. Método de isca para recuperação e quantificação de Rhizoctonia no solo de jardim clonal e substrato de enraizamento de Eucalyptus. Fitopatologia Brasileira 23:278. 1998. (Resumo).

SANFUENTES, E.A. Caracterização de isolados, flutuação populacional e controle biológico de Rhizoctonia spp. em jardim clonal de Eucalyptus. (Tese de Doutorado). Viçosa, MG, UFV, Imprensa Universitária, 2000. 